\title{
SUSTENTABILIDADE E DESENVOLVIMENTO SUSTENTÁVEL: ALCANCE DOS INSTITUTOS NAS FUNÇÕES ESTATAIS DE REGULAÇÃO, EXECUÇÃO E JURISDIÇÃO
}

\author{
SUSTAINABILITY AND SUSTAINABLE DEVELOPMENT: REACH OF \\ INSTITUTIONS IN THE STATE FUNCTIONS OF REGULATION, \\ IMPLEMENTATION AND JURISDICTION
}

\author{
Maria Carolina Carvalho de Almendra Freitas ${ }^{1}$ \\ Lorena de Melo Freitas ${ }^{2}$ \\ Gustavo Henrique Rocha de Macedo $^{3}$
}

\begin{abstract}
Resumo
O artigo faz breve apanhado dos conceitos de sustentabilidade e desenvolvimento social. Aborda as faces ambiental, social e econômica da sustentabilidade, além de seus subprincípios e sua matriz constitucional. Faz digressão sobre a reflexividade política do perigo, para se despertar a consciência social dos riscos trazidas pelas novas tecnologias. Discute o papel do Estado moderno, tanto no aspecto normativo, como os impactos gerados
\end{abstract}

\footnotetext{
1 Graduação em DIREITO pelo CENTRO DE ENSINO UNIFICADO DE TERESINA - CEUT (2003); ESPECIALIZAÇÃO em DIREITO PÚBLICO e em DIREITO PRIVADO pela UNIVERSIDADE FEDERAL DO PIAUÍ - UFPI (2004), MESTRADO em DIREITO INTERNACIONAL E ECONÔMICO pela UNIVERSIDADE CATÓLICA DE BRASÍLIA - UCB (2012); DOUTORANDA em DIREITO POLÍTICO E ECONÔMICO do programa de pós-graduação stricto sensu da UNIVERSIDADE PRESBITERIANA MACKENZIE - UPM. Profissinalmente atuou como advogada no escritório Moisés Reis Advogados Associados

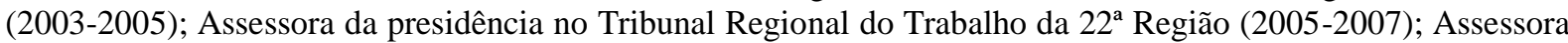
da presidência do Conselho do Serviço de Apoio a Pequenas e Micro Empresas do Piauí - SEBRAE-PI (20152017); Professora substituta na Universidade Estadual do Piauí - UESPI (2010-2011), no Centro de Ensino Superior do Vale do Parnaíba - CESVALE (2010-2017) e na Faculdade Integral Diferencial - Facid Wyden (2016-2018).

2Professora dedicação exclusiva da UFPB (Associada I), ensinando na Graduação (Hermenêutica Jurídica, Direito Internacional Privado) e Pós-Graduação em Direito - Mestrado e Doutorado (Metodologia, Teoria Geral do Direito). Membro do GT Ética e Cidadania da ANPOF. Graduada (UNICAP), Mestra e Doutora (UFPE) em Direito. Desenvolve pesquisas voltadas à atividade judicial desde o mestrado quando defendeu Dissertação intitulada ?Ideologia e direito: uma pesquisa empírica sobre a Associação Juízes para a Democracia? e no Doutorado com tese sobre a formação da decisão por juízes e tribunais sob título ?O realismo jurídico como pragmatismo: A retórica da tese realista de que direito é o que os juízes dizem que é direito?. Tem livros publicados e organizou obras coletivas sobre estas temáticas, tendo, para realização de suas atividades fundado o Grupo de Pesquisa ligado ao PPGCJ/UFPB: ?Realismo Jurídico?. Participa como pesquisadora de outros grupos de pesquisa ("Marxismo e Direito", "Pragmatismo Jurídico, Teorias da Justiça e Direitos Humanos" e "Fundamentos e Métodos do Pragmatismo: uma abordagem interdisciplinar dos fenômenos jurídicos") e tem como foco de pesquisa os seguintes temas: Realismo jurídico, ideologia, retórica, teoria geral, filosofia e sociologia do direito. A pesquisa de Pós-doutorado se intitulou: Espaços jurídicos emancipadores e inclusão como direito ao desenvolvimento sociopolítico: Uma crítica anisiana acerca das interfaces da pós-graduação com a educação básica em atenção à meta de 2007/2008 da CAPES.

${ }^{3}$ Promotor de Justiça no Estado do Paraná. Mestrando em Direito Empresarial e Cidadania do Centro Universitário Curitiba - UNICURITIBA.
} 
pelo exercício de suas atividades materiais. Finaliza apresentando alguns casos em que o tema da sustentabilidade foi debatido em julgamentos dos Tribunais Superiores.

Palavras-chave: Sustentabilidade. Matrizes constitucionais. Estado contemporâneo.

\begin{abstract}
The article briefly reviews the concepts of sustainability and social development. It addresses the environmental, social and economic aspects of sustainability, in addition to its sub-principles and constitutional grounds. Digress on the political reflexivity of danger, to awaken social awareness of the risks brought by new technologies. It discusses the role of the modern State, both in the normative aspect, and the impacts generated by the exercise of its material activities. It concludes by presenting some cases in which the theme of sustainability was discussed in Superior Court judgments.
\end{abstract}

Key-words: Susteinability; constitutional grounds; contemporary State.

\title{
1. BREVE INTRODUÇÃO
}

Sustentabilidade é dos temas mais debatidos na atualidade, pois inserido nas agendas econômica, ambiental e social. O papel do Estado para efetivar a sustentabilidade não se restringe, pois, ao campo regulatório da disciplina das relações do cidadão e dos corpos sociais com o ambiente. Com efeito, o próprio Estado, ao impactar a natureza com suas atividades, também é obrigado a adotar práticas ambiental, econômica e socialmente sustentáveis.

Prega-se que as novas tecnologias e os novos conhecimentos científicos são ferramentas a serviço do Estado e da sociedade, facilitadoras do desenvolvimento sustentável (social, econômico e ambiental). Mas, se eles inegavelmente têm trazido melhorias na qualidade de vida das pessoas, por outro lado têm efeitos colaterais, por vezes imprevistos. A sociologia de risco pode auxiliar nessa reflexão, nomeadamente ao sugerir o pensamento da reflexividade política do perigo, e tratar ciência da probabilidade e do desenvolvimento de novas matrizes de responsabilidade.

O desenvolvimento sustentável também avança sobre os campos social e econômico, o que tem a ver com a implementação do bem-estar da população, mediante ampliação de acesso à educação, cultura, seguridade social e, obviamente, asseguramento ao ambiente saudável. Contudo, isso exige recursos materiais, afinal os direitos têm custos, e é por isso que o Estado está obrigado à execução de planos de governança, a fim de que seja mais eficaz, eficiente e efetivo (gaste menos e produza mais) e, sem olvidar de regular e exigir que os 
particulares, em suas relações privadas, respeitem ao próximo. São, como se percebe, facetas do postulado da dignidade humana.

Para se demonstrar a extensão do tema, também serão mencionadas algumas experiências em que sustentabilidade e desenvolvimento sustentável foram objeto de debates no Supremo Tribunal Federal e Superior Tribunal de Justiça: responsabilidade civil subsidiária do Estado por dano ambiental (STJ - AgInt no REsp 1326903/DF e REsp 1376199/SP), proibição do uso industrial do amianto (STF - ADI 3470) e limites de exposição humana ao campo eletromagnético das linhas de transmissão de energia elétrica (STF - RE 627189).

O objetivo, enfim, é situar a sustentabilidade no cenário do Estado moderno, desdobrando-se seu conceito e indicando, em breves palavras, onde seus principais aspectos tocam na atividade do Poder Público.

\title{
2. SUSTENTABILIDADE E DESENVOLVIMENTO SUSTENTÁVEL - NOÇÕES GERAIS E DIMENSÃO TRANSNACIONAL
}

Ensinam ANTUNES DE SOUZA e PAVAN (2015, p. 11) que:

\begin{abstract}
sustentabilidade é uma concepção que deriva de preservação, de restabelecimento social, econômico e ambiental do ecossistema ameaçado pelas atitudes insanas do ser humano. Uma forma de expressar uma preocupação em preservar, em conservar recursos naturais para uma geração presente e futura. O termo sustentabilidade significa a preservação de determinado bem, a conservação de determinado material ou matéria-prima para a fabricação do mesmo bem. É, ainda, conservação de determinados produtos, bens, materiais ou imateriais, com o intuito de não perdê-lo com o passar dos tempos, evitando-se, assim, a escassez ou a extinção de bens necessários.
\end{abstract}

É sustentável, em outras palavras, o processo voltado à construção de sociedade global apta a se perpetuar, mantendo patamar mínimo de dignidade humana.

Está-se, portanto, diante do desafio da obtenção de equilíbrio entre crescimento econômico, com a correspondente melhoria da qualidade de vida das pessoas, e a preservação do ambiente natural. $\mathrm{O}$ uso desmedido de recursos naturais, para além de piorar a vida atual (conflito intrageracional), pode ter como consequência a subtração de determinado bem das gerações futuras (conflito intergeracional). Daí a ideia de sustentabilidade, que permeia crescimento duradouro, opondo-se à indesejável efemeridade.

Há relação entre fim e meio entre ela (a sustentabilidade) e o desenvolvimento sustentável, que é aquele que "encontra as necessidades atuais sem comprometer a 
habilidade das futuras gerações de atender suas próprias necessidades” (sustainable development, which implies meeting the needs of the present without compromising the ability of future generations to meet their own needs), conforme definição do relatório da Comissão de Meio Ambiente e Desenvolvimento da Organização das Nações Unidas, de 11 de dezembro de 1987.

O mesmo documento trouxe importantes contribuições para afirmar-se que a noção do desenvolvimento sustentável não é limitada à preservação dos recursos naturais. Suas metas são mais ambiciosas, incluindo-se nesse rol a manutenção da paz, a erradicação da pobreza, a equalização do crescimento populacional com a conservação das fontes de recursos naturais, a reorientação das novas tecnologias e o gerenciamento de riscos econômicos e ambientais, cujas análises devem ser fundidas.

Tais aspectos são dissecados por FARIA (2011, p. 17), ao enumerar:

(i) sustentabilidade social: melhoria da qualidade de vida da população, equidade na distribuição de renda e de diminuição das diferenças sociais, com participação e organização popular; (ii) sustentabilidade econômica: públicos e privados, regularização do fluxo desses investimentos, compatibilidade entre padrões de produção e consumo, equilíbrio de balanço de pagamento, acesso à ciência e tecnologia; (iii) sustentabilidade ecológica: o uso dos recursos naturais deve minimizar danos aos sistemas de sustentação da vida: redução dos resíduos tóxicos e da poluição, reciclagem de materiais e energia, conservação, tecnologias limpas e de maior eficiência e regras para uma adequada proteção ambiental; (iv) sustentabilidade cultural: respeito aos diferentes valores entre os povos e incentivo a processos de mudança que acolham as especificidades locais; (v) sustentabilidade espacial: equilíbrio entre o rural e o urbano, equilíbrio de migrações, desconcentração das metrópoles, adoção de praticas agrícolas mais inteligentes $e$ não agressivas à saúde e ao ambiente, manejo sustentável das florestas $e$ industrialização descentralizada; (vi) sustentabilidade política; no caso do Brasil, a evolução da democracia representativa para sistemas descentralizados $e$ participativos, construção de espaços públicos comunitários, maior autonomia dos governos locais e descentralização da gestão de recursos; (vii) sustentabilidade ambiental: conservação geográfica, equilíbrio de ecossistemas, erradicação da pobreza e da exclusão, respeito aos direitos humanos e integração social.

A rigor, poder-se-iam reduzir esses desdobramentos às dimensões clássicas da sustentabilidade, quais sejam, ambiental, social e econômica. Com efeito, os aspectos ambiental e ecológico parecem indissociáveis, ao passo que os aspectos cultural, espacial e político são perfeitamente enquadráveis na ampla moldura das faces social e econômica da sustentabilidade.

A sustentabilidade, ainda, tem uma pretensão transnacional. Mister que as nações assumam compromissos de preservação ambiental, acoplados ao respeito aos direitos humanos, à distribuição de riquezas, à erradicação da pobreza, à integração dos povos. Em outros termos, não é dado que determinado país preserve seu ambiente às custas da 
exploração predatória das fontes naturais alheias, ou que a incúria com seus ecossistemas atinja outros Estados soberanos, tampouco que suporte seu crescimento econômico na utilização do trabalho indigno eventualmente tolerado em outra nação. A humanidade requer a construção de ética compreensiva dos problemas globais, a fim de se viabilizar a construção de um novo momento civilizatório marcado pela solidariedade. Afinal, tragédias ambientais e humanitárias não respeitam fronteiras.

O desenvolvimento sustentável é objeto de outros documentos internacionais, valendo realçar, por sua atualidade, "Transformando o Nosso Mundo: A Agenda 2030 para o Desenvolvimento Sustentável", concebida em Nova York, no ano de 2015. A carta contém dezessete objetivos, além de cento e sessenta e nove metas, a serem perseguidas pelas nações signatárias ${ }^{4}$.

Esse breve panorama sobre a amplitude conceitual da sustentabilidade permite avançar sobre outros aspectos, destacando-se, aqui, as novas tecnologias que, se de um lado trazem aparente conforto, de outro podem acarretar riscos imprevistos.

\footnotetext{
${ }^{4}$ A título de notícia (pois os modestos limites deste trabalho não permitem maior profundidade) os objetivos do desenvolvimento sustentável são: 1. Erradicação da pobreza - Acabar com a pobreza em todas as suas formas, em todos os lugares; 2. Fome zero e agricultura sustentável - Acabar com a fome, alcançar a segurança alimentar e melhoria da nutrição e promover a agricultura sustentável. 3. Saúde e bem-estar - Assegurar uma vida saudável e promover o bem-estar para todos, em todas as idades. 4. Educação de qualidade - Assegurar a educação inclusiva, e equitativa e de qualidade, e promover oportunidades de aprendizagem ao longo da vida para todos. 5. Igualdade de gênero - Alcançar a igualdade de gênero e empoderar todas as mulheres e meninas. 6. Água limpa e saneamento - Garantir disponibilidade e manejo sustentável da água e saneamento para todos. 7. Energia limpa e acessível - Garantir acesso à energia barata, confiável, sustentável e renovável para todos. 8. Trabalho de decente e crescimento econômico - Promover o crescimento econômico sustentado, inclusivo e sustentável, emprego pleno e produtivo, e trabalho decente para todos. 9. Inovação infraestrutura - Construir infraestrutura resiliente, promover a industrialização inclusiva e sustentável, e fomentar a inovação. 10. Redução das desigualdades - Reduzir as desigualdades dentro dos países e entre eles. 11. Cidades e comunidades sustentáveis - Tornar as cidades e os assentamentos humanos inclusivos, seguros, resilientes e sustentáveis. 12. Consumo e produção responsáveis - Assegurar padrões de produção e de consumo sustentáveis. 13. Ação contra a mudança global do clima - Tomar medidas urgentes para combater a mudança climática e seus impactos. 14. Vida na água - Conservação e uso sustentável dos oceanos, dos mares, e dos recursos marinhos para o desenvolvimento sustentável. 15. Vida terrestre - Proteger, recuperar e promover o uso sustentável dos ecossistemas terrestres, gerir de forma sustentável as florestas, combater a desertificação, deter e reverter a degradação da Terra e deter a perda da biodiversidade. 16. Paz, justiça e instituições eficazes - Promover sociedades pacíficas e inclusivas par ao desenvolvimento sustentável, proporcionar o acesso à justiça para todos e construir instituições eficazes, responsáveis e inclusivas em todos os níveis. 17. Parcerias e meios de implementação - Fortalecer os meios de implementação e revitalizar a parceria global para o desenvolvimento sustentável.
} 


\section{MATRIZES CONSTITUCIONAIS - MEIO AMBIENTE, DIGNIDADE HUMANA E CIÊNCIA}

A Constituição da República contempla a sustentabilidade em vários de seus capítulos. Para ilustração, adiante serão mencionadas algumas das passagens mais emblemáticas.

O preâmbulo da Constituição apresenta a fundação de

um Estado Democrático, destinado a assegurar o exercício dos direitos sociais e individuais, a liberdade, a segurança, o bem-estar, o desenvolvimento, a igualdade e a justiça como valores supremos de uma sociedade fraterna, pluralista e sem preconceitos, fundada na harmonia social e comprometida, na ordem interna e internacional, com a solução pacífica das controvérsias(...).

As alusões a segurança, bem-estar, desenvolvimento, igualdade e justiça, são significativas porque o preâmbulo é a Constituição da Constituição. Como ensina COELHO (2010, P. 73/74)

\footnotetext{
"lê-se em Peter Häberle, por exemplo, que essas palavras, que inauguram os textos das constituições, longe de serem fórmulas vazias, funcionam como importantes 'pontes do tempo', seja para evocar ou esconjurar o passado, a depender das circunstâncias históricas de cada processo constituinte; seja para falar ao presente, ocasionalmente orientando desejos; seja, enfim, para contemplar tanto o presente quanto o futuro e, com relação a este, ademais, para antecipar, quanto possível, o encontro de um povo com esse almejado porvir."
}

Por isso se pode afirmar que o desenvolvimento constante e sustentável é desejo da ordem vigente, é o futuro que se busca.

Ao definir os fundamentos da república, a Carta Magna consagra a cidadania e a dignidade da pessoa humana, o que claramente vai ao encontro da dimensão social da sustentabilidade (art. $1^{\circ}$, incisos II e III).

Mais adiante, o texto constitucional prevê como princípios da ordem econômica a função social da propriedade, a defesa do consumidor, a defesa do meio ambiente, inclusive mediante tratamento diferenciado conforme o impacto ambiental dos produtos e serviços e de seus processos de elaboração e prestação, a redução das desigualdades regionais e sociais e a busca do pleno emprego (art. 170).

Quando trata da política urbana, a Constituição proclama que o Poder Público ordenará o desenvolvimento das funções sociais da cidade, a fim de garantir o bem-estar de seus habitantes (art. 182). 
Ao tratar da ciência, tecnologia e inovação, o art. $218, \S 2^{\circ}$, estabelece que " $\boldsymbol{a}$ pesquisa tecnológica voltar-se-á preponderantemente para a solução dos problemas brasileiros e para o desenvolvimento do sistema produtivo nacional e regional”. A dimensão tecnológica, portanto, é vislumbrada como instrumento para obtenção da sustentabilidade nos planos econômico, social e ambiental.

Por fim, o art. 225 consagra como direito fundamental o meio ambiente ecologicamente equilibrado, bem de uso comum do povo e essencial à sadia qualidade de vida, impondo-se ao Poder Público e à coletividade o dever de defendê-lo e preservá-lo para as presentes e futuras gerações. O catálogo de obrigações impostas ao Poder Público para tutela do ambiente (rectius, sustentabilidade ambiental) é extenso, valendo citar: preservar e restaurar os processos ecológicos essenciais e prover o manejo ecológico das espécies e ecossistemas; preservar a diversidade e a integridade do patrimônio genético do País e fiscalizar as entidades dedicadas à pesquisa e manipulação de material genético; definir, em todas as unidades da Federação, espaços territoriais e seus componentes a serem especialmente protegidos, vedada qualquer utilização que comprometa a integridade dos atributos que justifiquem sua proteção; exigir, para instalação de obra ou atividade potencialmente causadora de significativa degradação do meio ambiente, estudo prévio de impacto ambiental, a que se dará publicidade; controlar a produção, a comercialização e o emprego de técnicas, métodos e substâncias que comportem risco para a vida, a qualidade de vida e o meio ambiente; promover a educação ambiental em todos os níveis de ensino e a conscientização pública para a preservação do meio ambiente; proteger a fauna e a flora, vedadas, as práticas que coloquem em risco sua função ecológica, provoquem a extinção de espécies ou submetam os animais a crueldade.

É desse plexo que Juarez Freitas extrai sua concepção de sustentabilidade, caracterizando-a como

princípio constitucional que determina, com eficácia direta e imediata, a responsabilidade do Estado e da sociedade pela concretização solidária do desenvolvimento material e imaterial, socialmente inclusivo, durável e equânime, ambientalmente limpo, inovador, ético e eficiente, no intuito de assegurar, preferencialmente de modo preventivo e precavido, no presente e no futuro, o direito ao bem-estar.

Há, assim, uma série de disposições que, abordando o desenvolvimento humano sob diversos enfoques, acabam mirando a mesma finalidade. Deveras, somente pode receber a tarja de sustentável o desenvolvimento que, ao tempo em que preserve o ambiente, dele 
tirando o essencial para a melhoria de qualidade de vida da população sem exaurir-lhe os recursos, seja apto a propiciar a dignidade humana.

Essa noção, que remonta a Kant, pode ser resumida com a afirmação de que toda pessoa deve ser considerada um fim em si mesma. BARROSO (2010, p. 150) bem sintetiza que:

a dignidade da pessoa humana é o valor e o princípio subjacente ao grande mandamento, de origem religiosa, do respeito ao próximo. Todas as pessoas são iguais e têm direito a tratamento igualmente digno. A dignidade da pessoa humana é a ideia que informa, na filosofia, o imperativo categórico kantiano, dando origem a proposições éticas superadoras do utilitarismo: a) uma pessoa deve agir como se a máxima da sua conduta pudesse transformar-se em uma lei universal; b) cada indivíduo deve ser tratado como um fim em si mesmo, e não como um meio para a realização de metas coletivas ou de outras metas individuais.

Levando o raciocínio adiante, é mister que o crescimento econômico seja atrelado ao implemento qualitativo (e não apenas extensivo, ou de longevidade) da vida humana, o que passa pela redução de desigualdades econômicas e sociais, somado à imprescindível tolerância às divergências culturais, de credo, enfim, aos projetos de vida de cada pessoa. Isso se dá mediante o respeito aos direitos fundamentais, sejam as liberdades públicas ou os prestacionais, sejam os de terceira, quarta ou quinta dimensão. $\mathrm{O}$ cumprimento dessas diretrizes, por conseguinte, não pode olvidar da exploração comedida dos recursos naturais, a fim de que suas fontes sejam preservadas, assegurando-se o progresso da qualidade de vida à atual e às próximas gerações de humanos que habitarão o planeta.

Embora rico, o arcabouço constitucional sobre o tema do desenvolvimento sustentável está longe de ser alcançado. A distância entre o almejado e a realidade é bem realçada por KRELL (2018), ao assinalar que:

a constituição normativa e a empírica exercem um efeito mútuo: a pretensão normativa somente pode ser cumprida na medida em que são realizados determinados fatores extrajurídicos. Pelas mesmas razões, parece ser exagerado chamar o texto constitucional brasileiro de 'Constituição ecológica' ou 'Constituição ambiental', para justificar tal titulação, a distância entre mandado constitucional e realidade político-administrativa simplesmente (ainda) é grande demais. Outros sugerem que o Estado ambiental, no Brasil, deveria ser compreendido como 'meta' ou 'parâmetro' a ser atingido, trazendo à tona uma série de discussões que otimizam processos de realização de aproximação do Estado ficto. Neste sentido, Perez-Luño tem razão quando afirma que a inegável dimensão utópica, sempre inerente aos ramos inovadores do direito, 'estimula os poderes públicos e serve de incentivo para opinião pública para o desenvolvimento daquelas metas ainda não alcançadas e que contrastam com as realidades que se desejam superar'. 
A realização do projeto constitucional de desenvolvimento sustentável pressupõe domínio e utilização de novos conhecimentos tecnológicos, a fim de se corrigirem danos causados no passado, e se evitarem que outros ocorram no presente e no futuro. No entanto, esses novos conhecimentos não necessariamente são benéficos, e o alerta sobre efeitos colaterais é feito pela sociologia do risco.

\section{AS NOVAS TECNOLOGIAS - SOCIEDADE DE RISCO}

Não há dúvidas de que os progressos da ciência têm ampliado a duração e a qualidade da vida das pessoas ao longo dos séculos. Para exemplificar essa melhoria, basta citar a maior capacidade de produção de alimentos e medicamentos, a difusão de meios de comunicação e transporte. No geral, tem-se a impressão de que as pessoas vivem mais e melhor.

Essas conquistas, todavia, não vieram dissociadas de implicações negativas, surgindo desse paradoxo o dilema da sociedade de risco, aquela que, segundo BECK (1991, p. 229) “designa uma época em que os aspectos negativos do progresso determinam cada vez mais a natureza das controvérsias que animam a sociedade”.

Basta cogitar-se de temas como a manipulação genética e a nano-tecnologia para se ter a noção do quão complexo é esse debate.

O primeiro grande problema é que os benefícios tecnológicos, via de regra, não são distribuídos de maneira igualitária. Em outros termos, não há necessária coincidência entre aqueles que auferem os benefícios com os que suportam os riscos. É oportuno chamar-se à colação o esclarecimento de GUARAGNI (2011, p. 77) ao afirmar que "as conquistas geradas por uma dada tecnologia, restrita a alguns, vêm acompanhadas de riscos que são distribuídos em favor de todos." Por outro lado, os perigos normalmente são invisíveis e, quando perceptíveis, há tendência de serem negados pelos mais próximos.

Outro problema é a impossibilidade de se preverem, com segurança, os perigos dos novos conhecimentos. Nesse sentido, observa uma vez mais BECK (2011, p. 250) que " $\boldsymbol{a}$ ciência dos dados e dos laboratórios jamais será capaz de suprimir a incerteza de probabilidades, que por definição nada exclui, e ela é cega às consequências que acompanham e ameaçam os seus sucessos.”

Por isso o autor sugere a necessidade do despertar da reflexividade política do perigo, que, em resumo, vem a ser a preocupação coletiva com os problemas de segurança causados pela produção. Nos conflitos ecológicos, invariavelmente agressor e ofendidos saem lesados, 
havendo apenas falsas e efêmeras vantagens, as quais se diluem ao longo do tempo. E quando a catástrofe ocorre, a preocupação do ofensor é de marginalizar os danos e torná-los localizados em determinado segmento. Essa técnica de neutralização, contudo, é temporária, e somente ao tempo em que as camadas médias do tecido social são atingidas é que o sistema político reagirá.

Os conflitos ecológicos desencadeados na sociedade de risco requerem mudanças de paradigmas no sistema de imputação de responsabilidades, a fim de que os interesses da população se sobreponham aos industriais. Nessa ordem de ideias, BECK (1991, p. 236) sugere:

a) modificação de ônus da prova, impondo-se a operadores das tecnologias o dever de explicação à opinião pública;

b) abertura de círculos de discussão e de peritos políticos, científicos e industriais ao pluralismo disciplinar, favorecendo as contra-perícias e o debate entre interessados;

c) reforma dos sistemas de responsabilidade civil e penal;

d) discussão transparente sobre lacunas em sistemas de seguros e falta de cobertura em atividades altamente tecnológicas;

e) estabelecimento de sistemas de responsabilidade regionais a causadores de dano (p. ex.: indústrias poluidoras que atingem a exploração do turismo);

f) estabelecimento de convenções coletivas entre poluidores e população regional, para indenização difusa.

O autor traz argumentos históricos, relatando que, no Século XIX, discutia-se acerca da responsabilidade por acidentes de trabalho, já que, no plano estritamente causal, vários fatores contribuem para determinado evento, havendo ambiguidade ontológica. Assim, “o problema da responsabilidade devia e deve ser regulado - como para a questão social - por acordos adquiridos por lutas, por contratos sociais, normas jurídicas. Essas experiências históricas devem ser aplicadas à ecologia” (2011, p. 237).

Mais à frente, alerta para a chamada encenação de riscos. Cuida-se de estratégia adotada pelos causadores do risco, buscando ocultá-lo com técnicas de atribuição de descrédito às alternativas (p. ex., produção de energia nuclear busca enfatizar os riscos do buraco na camada de ozônio, decorrente da emissão de gás carbônico).

A realidade é complexa porque os riscos são causados pelo desenvolvimento. As riquezas são tangíveis e perceptíveis, mas os danos, em regra, dependem da apreciação de experts para serem diagnosticados, cujas análises, no geral, acabam por isolar uma causa como a grande causadora. A estratégia é a de restringir responsabilidades pela catástrofe. 
A reflexividade politica do perigo, portanto, é valiosa na medida em que provoca instituições e agita terrenos aparentemente estabilizados, no afã de se rediscutirem velhas práticas não mais admissíveis.

Algo que, de certa forma, retarda o despertar dessa reflexividade é a não percepção sensorial do perigo. BECK (2011, p. 246) explica que

\begin{abstract}
é apenas por meio de instrumentos de medida complicados, frequentemente custosos, e de procedimentos metódicos, que podemos decidir sobre a natureza e o grau do perigo. De certa forma, os perigos em questão substituem os órgãos de percepção individuais por órgãos estatais, burocráticos, científicos. Nossos olhos tornam-se instituições de pesquisas, nossos ouvidos viram instituições de saúde pública e nossas mãos são os ministérios do meio ambiente - ministérios que lavam as mãos em inocência!
\end{abstract}

Esse fenômeno somente pode ser combatido com o conhecimento, a consciência do cidadão a respeito dos perigos cotidianos, evitando-se assim a desapropriação dos sentidos, assim como a infantilização dos cidadãos.

BECK propõe (2011, p. 252), assim, que a política invada o campo antes exclusivo da ciência de laboratório:

Uma política de longo prazo contra os perigos exige frear o desenvolvimento das tecno-ciências, abrir possibilidades de curvá-lo, de revisá-lo e de estabelecer responsabilidades; em resumo, supõe uma capacidade de buscar acordos, logo de estender a democracia para domínios até então resguardados da ciência, da técnica e da indústria.

A reflexividade politica do perigo descortina-se necessária para que os espaços de debate público discutam os avanços e meçam (ainda que sob o influxo da probabilidade) os impactos das novas tecnologias. Não se cogita, por óbvio, de retrocessos nesse campo: o desafio que se põe é que as tecnologias propiciem sustentabilidade, gerando riscos menores, cuja avaliação não pode ficar restrita à elite científica, por vezes comprometida com o poder econômico.

São oportunas as palavras de SÉLLOS-KNOERR e KNOERR (2018, p. 48), que citam Hannah Arendt para expor que:

o desenvolvimento é um processo incessante na história das sociedades humanas, o qual se desenvolve em fases que 'ocorrem diariamente no âmbito da política prática, sujeitas ao acordo de muitos; jamais poderiam se basear em considerações teóricas ou na opinião de uma só pessoa, como se tratasse de problemas para os quais só existe uma solução possível. 
É por isso, por exemplo, que o licenciamento ambiental de grandes empreendimentos contempla audiências públicas ${ }^{5}$. Cuida-se de locus público, propício ao debate entre empreendedor, Poder Público e sociedade, que via de consequência estimula a reflexividade política do perigo.

Não se pode desprezar que o Direito Positivo nacional apresenta exemplos em que se verifica espaço para a reflexividade política. Valem citar: a responsabilidade objetiva do causador do dano ambiental (art. 14, $\S 1^{\circ}$, da Lei Federal no 6.938/81) e de danos nucleares (art. 21, inciso XXIII, alínea “d”, da Constituição), possibilidade de inversão do ônus da prova nas ações de responsabilidade por dano causado ao consumidor (art. $6^{\circ}$, inciso VIII, do Código de Defesa do Consumidor), distribuição dinâmica do ônus da prova (art. 373, parágrafo $1^{\circ}$, do Código de Processo Civil), audiências públicas nos processos objetivos de controle de constitucionalidade (art. $9^{\circ}, \S 1^{\circ}$, da Lei Federal n ${ }^{\circ} 9.868 / 99$ ).

O que se pretende afirmar é que o desenvolvimento ambientalmente, socialmente e economicamente sustentável realmente pressupõe novas tecnologias, meios indispensáveis para o alcance dessa meta. Mas, o público deve dialogar com a academia e com o capital, para compreensão dos custos e dos benefícios decorrentes dos novos produtos do conhecimento humano.

\section{FUNÇÃO REGULATÓRIA - A BUSCA DO EQUILÍBRIO}

A história é repleta de movimentos pendulares, impulsionados que são por ideologias predominantes nas respectivas eras. $O$ Estado ora se faz maior, intervencionista, protagonizando o setor produtivo, ora se retrai para assumir o papel regulador e subsidiário. $\mathrm{Na}$ tutela dos direitos fundamentais, há certo consenso que as três primeiras dimensões (ou gerações) passaram pelas liberdades públicas (Estado liberal), sobrevindo os direitos sociais (Estado de bem-estar social) e pela defesa de direitos transindividuais, não se desconhecendo, ainda, as teses que proclamam a existência das quarta e quinta gerações (Estado moderno).

Atentando-se aos limites deste esboço, cabe assinalar que atualmente se vive sob o signo do neoliberalismo, sucessor do Estado de bem-estar social. Uma vez mais se recorre a BARROSO (2010, p. 67), que didaticamente explica que

\footnotetext{
${ }^{5}$ A Resolução n. 09/1987, do Conselho Nacional do Meio Ambiente, proclama que "Sempre que julgar necessário, ou quando for solicitado por entidade civil, pelo Ministério Público, ou por 50 (cinqüenta) ou mais cidadãos, o Órgão de Meio Ambiente promoverá a realização de audiência pública”.
} 
esse Estado da busca do bem-estar social, o welfare-state, chegou ao final do século amplamente questionado na sua eficiência, tanto para gerar e distribuir riquezas como para prestar serviços públicos. A partir do início da década de 80, em diversos países ocidentais, o discurso passou a ser o da volta ao modelo liberal, o Estado mínimo, o neoliberalismo. Dentre seus dogmas, que com maior ou menor intensidade correram mundo, estão a desestatização e desregulamentação da economia, a redução das proteções sociais ao trabalho, a abertura de mercado e a inserção internacional dos países, sobretudo através do comércio. O neoliberalismo pretende ser a ideologia da pós-modernidade, um contra-ataque do privatismo em busca do espaço perdido pela expansão do papel do Estado.

No Brasil, esse movimento se tornou perceptível em meados da década de 1990, com sucessivas reformas constitucionais deram o perfil regulador ao Estado. Ganhou corpo a chamada administração policêntrica, com a criação das agências reguladoras, órgãos autônomos e dotados de poder normativo para a expedição de ordenamentos setoriais, como a ANVISA, ANS, ANATEL, ANTT, entre outras. A preocupação não era apenas de se diminuir o tamanho do Estado, mas de se atribuir gestão técnica a pontos sensíveis da economia, assegurando-se estabilidade econômica, que pudesse estar imune ao calendário eleitoral, com a pretensão de se atraírem investimentos privados. Ensina BINENBOJM (2008) que

o chamado compromisso regulatório (regulatory commitment) era, na prática, uma exigência do mercado para a captação de investimentos. Em países cuja história recente foi marcada por movimentos nacionalistas autoritários (de esquerda e direita), o risco de expropriação e de ruptura dos contratos é sempre um fantasma que assusta ou espanta os investidores estrangeiros. Assim, a implantação de um modelo que subtraísse o marco regulatório do processo político-eleitoral se erigiu em verdadeira tour de force da reforma do Estado. Daí a ideia de blindagem institucional de um modelo que resistisse até a uma vitória da esquerda em eleição futura.

Nesse espectro, o Estado concede maior flexibilização às relações privadas, pela via da deslegalização, atribuindo às autoridades administrativas independentes, não subordinadas ao Executivo central, a competência regulamentar. Embora as amarras fossem diminuídas, buscava-se que os regramentos fossem mais estáveis, a partir da desvinculação das agências reguladoras do centro de gravidade do Poder. O movimento também incentivou polos de autorregulação, concedendo aos atores do mercado a possibilidade de disciplinarem certos nichos a partir de códigos de conduta.

A relação do tema com a sustentabilidade é evidente: na medida em que se busca garantir a estabilidade da regulamentação, pois os mandatos dos chefes das agências reguladoras não coincidem com os da chefia do Executivo, e nem eram eles demissíveis $a d$ nutum, buscaram-se recursos internacionais que pudessem alavancar o crescimento 
econômico de forma perene, daí se retirando a conexão entre desenvolvimento econômico e social.

Vem ao encontro dessas proposições a chamada coopetição, que apregoa sinergia institucional entre Estado e sociedade. BARROSO FILHO (2018, p. 29) ensina que a coopetição é o:

\begin{abstract}
misto de cooperação e competição - assunto abordado pelos professores de economia Bradenburger (Harvard Business School) e Nalebuff (Yale School of Management). O Estado embora seja um competidor, que sempre ganha a sua parte, uma vez que os tributos são obrigatórios, a ação do Estado, em determinados contextos, pode ser entendida como 'coopetição'. Isto é, compete pelo dinheiro, quando cobra tributos, mas coopera com as empresas e a sociedade, quando o dinheiro dos tributos é investido em redes de transporte, fornecimento de energia, telecomunicações, estabilidade da moeda e assim por diante.
\end{abstract}

A lógica é relativamente simples: o Estado se concentra na prestação de serviços públicos (principalmente educação, segurança, saúde, assistência e seguro social, infraestrutura) e se abstém de concorrer no mercado, regulando-o no essencial, confiando que a estabilidade econômica estimulará a competição, o aumento da produção, com o consequente aumento de emprego e renda da população. Com as engrenagens em funcionamento, o motor do desenvolvimento traria um bom efeito colateral, que seria a redução da demanda por serviços públicos.

Contudo, esse desenvolvimento (que acaso se efetivasse mereceria ser rotulado como sustentável) está no meio do caminho, o que não significa que se deva abandoná-lo. É preciso prosseguir na busca da calibragem ideal, a fim de que o Estado não intervenha nas relações particulares além do essencial para a defesa da dignidade humana, e, no que toca às prestações que lhe são exigíveis, seja mais eficiente (gaste menos e produza mais).

\title{
5. ADMINISTRAÇÃO PÚBLICA SUSTENTÁVEL: ALGUMAS BOAS NOTÍCIAS
}

O Estado brasileiro ainda é enorme e disfuncional. Problemas como atribuições superpostas, mau dimensionamento de estruturas físicas e funcionais (ora insuficientes, ora exageradas), falta de planejamento, tráfico de influências, loteamento da administração pública, escolha equivocada de prioridades são apenas alguns exemplos da constelação de problemas que estão impregnados no cotidiano do Poder Público, e o levam à ineficiência e consequente descrédito. 
Cresce, assim, o apelo pela instituição de modelos de governança. Instituto oriundo do setor privado, a governança se refere à metodologia de direção e controle das instituições. Busca-se a proteção das finalidades do órgão, ou seja, que seus dirigentes não se desviem das expectativas dos mandatários.

Essas ideias vêm sendo adaptadas para que sejam aplicadas no setor público. Sobre o tema, há recente estudo de RIBEIRO NARDES (2018, p. 333), no qual se define a governança pública como:

a capacidade que os governos têm, utilizando-se de um conjunto de instrumentos e ferramentas adequadas, de: assegurar que a vontade dos cidadãos seja capturada nos planejamentos estratégicos, táticos e operacionais; selecionar pessoas e instituir normas e processos adequados para executar as ações planejadas; alcançar e controlar os resultados previstos; estabelecer indicadores de desempenho para verificar o quanto foi ou não alcançado; e divulgar todas essas etapas à sociedade.

Mais à frente, o doutrinador explica os motivos pelos quais a governança pública é fator na equação que tem como produto o desenvolvimento sustentável:

\begin{abstract}
Para atender ao preceito constitucional e alcançar o tão almejado desenvolvimento, conjugando crescimento econômico com qualidade de vida da população, o Brasil precisa vencer uma série de desafios, dentre eles a melhoria da educação, o incentivo à inovação tecnológica, a diminuição da desigualdade regional, a racionalização dos gastos públicos e a realização de obras de infraestrutura. A superação desses desafios requer o estabelecimento de uma estrutura de governança efetiva, constituída de mecanismos de transparência, planejamento estratégico, controle da execução e avaliação de resultados, com vistas a assegurar a supremacia da vontade popular sobre o interesse dos gestores públicos e de determinados grupos privados.
\end{abstract}

Não é difícil associar esses preceitos ao ideário neoliberal. O Estado deve ser mínimo no tamanho, mas máximo na excelência. Isso somente tem lugar com ações planejadas e controle de resultados. Já se veem lampejos da cultura de governança no Brasil.

No plano federal, o Decreto $\mathrm{n}^{\circ}$ 9.203/2017 “dispõe sobre a política de governança da administração pública federal direta, autárquica e fundacional." $\mathrm{O}$ decreto fixa como princípios de governança públicas capacidade de resposta, integridade, confiabilidade, melhoria regulatória, prestação de contas e responsabilidade e transparência. São princípios afetos à sustentabilidade (econômica, ambiental ou social), na medida em que direcionadas à eficiência estatal, e a busca de sua viabilidade econômica.

Nesse contexto, podem ser relacionadas iniciativas que, malgrado focadas no aspecto ambiental, têm a ver com a ideia de governança, porque dão outro enfoque às compras da administração, que, para serem melhores, não são necessariamente as mais baratas. É a 
administração pública buscando a diminuição do impacto ambiental de seu consumo. A questão não é lateral, na medida em que estudos apontam que as aquisições de bens e serviços, por órgãos públicos, representam entre 10 e $15 \%$ do PIB nacional.

Recorda-se, inicialmente, do Plano de Ação para Produção e Consumo Sustentáveis PPCS2 -, lançado em novembro de 2011 pelo Ministério do Meio Ambiente. Esse foi o documento guia das ações de governo, do setor produtivo e da sociedade que direciona o Brasil para padrões mais sustentáveis de produção e consumo, com redução da pobreza. $\mathrm{O}$ plano se baseia na chamada economia verde, que

\footnotetext{
segundo o Programa das Nações Unidas para o Meio Ambiente (PNUMA), é o modelo que trará maior bem-estar e equidade social, enquanto reduz significativamente os riscos ambientais e a escassez de recursos naturais. O debate mundial sobre Economia Verde está refletido no Plano de Ação para Produção e Consumo Sustentáveis, que se torna um instrumento da transição para este novo modelo. ${ }^{6}$
}

Tem grande visibilidade a proliferação dos processos virtuais. Tomando por base os processos judiciais, verifica-se que imenso ganho em velocidade, com grande supressão de atos cartoriais, eliminação de remessas físicas, além dos custos prosaicos com papel, tinta, e a posterior guarda de documentos (arquivos judiciais). A despeito de alguns efeitos periféricos, cujo mais preocupante é uma certa "pasteurização" da justiça, os ganhos em termos de efetividade são inequívocos, sendo louvável a diminuição do passivo ambiental.

No Estado do Paraná, a Lei Estadual n. ${ }^{\circ}$ 15.608/2007, que estabelece normas sobre licitações, contratos administrativos e convênios prevê que a realização de contratos e convênios está subordinada ao princípio da sustentabilidade ambiental (art. $5^{\circ}$, inciso I), e que os convênios devem ser antecedidos de plano de trabalho que observe a sustentabilidade ambiental (art. 134, $\S 2^{\circ}$ ). A lei é regulamentada pelo Decreto $.^{\circ} 4.993 / 2016$, que determina que a licitação para aquisição de bens e contratação de serviços deve prever, em seu edital, que:

a) os bens sejam constituídos, no todo ou em parte, por material reciclado, atóxico, biodegradável, conforme normas específicas da ABNT;

b) sejam observados os requisitos ambientais para a obtenção de certificação do Instituto Nacional de Metrologia, Normalização e

\footnotetext{
6 Apresentação do PPCA, disponível no site: http://www.mma.gov.br/responsabilidade-
} socioambiental/producao-e-consumo-sustentavel/plano-nacional.html. Acesso em 24/02/2019. 
Qualidade Industrial - INMETRO, como produtos sustentáveis ou de menor impacto ambiental em relação aos seus similares;

c) os bens devam ser, preferencialmente, acondicionados em embalagem individual adequada, com o menor volume possível, que utilize materiais recicláveis, de forma a garantir a máxima proteção durante o transporte e o armazenamento;

d) os bens não contenham substâncias perigosas em concentração acima da recomendada na diretiva RoHS (Restriction of Certain Hazardous Substances), tais como mercúrio $(\mathrm{Hg})$, chumbo $(\mathrm{Pb})$, cromo hexavalente $(\mathrm{Cr}(\mathrm{VI}))$, cádmio $(\mathrm{Cd})$, bifenil-polibromados (PBBs), éteres difenil-polibromados (PBDEs).

Percebe-se que a lei estadual de licitações tem espectro mais amplo do que a Lei Federal n. ${ }^{\circ}$ 8.666/93, pois essa faz acanhadas menções a avaliação de impactos ambientais quando da elaboração de projetos (artigos $6^{\circ}$, inciso IX e 12, inciso VII), para além de catalogar o desenvolvimento nacional sustentável como um dos objetivos das licitações.

No âmbito da Justiça do Trabalho, seu Conselho Superior elaborou guia para inclusão de critérios de sustentabilidade nas contratações realizadas por órgãos desse ramo do Judiciário.

Em termos concretos, é digna de exaltação recente licitação promovida pela Advocacia-Geral da União, por sua unidade do Rio Grande do Sul, para aquisição de papel. O edital do certame consagrou os critérios de sustentabilidade do projeto Compras Públicas Sustentáveis e Rotulagem Ambiental (SPPEL, na sigla em inglês), uma iniciativa da ONU Meio Ambiente. Segundo noticiado,

\begin{abstract}
entre os vários critérios de seleção, o papel tinha que ser do tipo 'não clorado' que não usa cloro em seu processo de branqueamento. $\mathrm{O}$ processo de produção também precisava atender a um limite de emissões de compostos orgânicos halogenados e organoclorados. O fabricante precisou ainda comprovar, junto ao Cadastro Técnico Federal do IBAMA, que possuía estação de tratamento de água e de efluentes, bem como um sistema de gestão de resíduos. Outro elemento que norteou a escolha da empresa fornecedora foi a garantia de condições decentes de trabalho entre seus profissionais, em acordo com a Convenção $n^{\circ} 155$ da Organização Internacional do Trabalho (OIT). ${ }^{7}$
\end{abstract}

As notícias, dessa forma, apontam para o encorpamento da noção de desenvolvimento sustentável do Estado, enquanto organismo realizador de atividades materiais que, inequivocamente, impactam os meios ambiental, econômico e social.

\footnotetext{
${ }^{7}$ Notícia veiculada no seguinte site, acessado em 18/10/2018: http://www.altosestudos.com.br/?p=57552
} 


\title{
6. DEBATES SOBRE SUSTENTABILIDADE NOS TRIBUNAIS SUPERIORES
}

Finaliza-se o estudo com breve referência a alguns casos em que a sustentabilidade foi tema de julgamentos dos Tribunais Superiores.

Inicia-se por decisão de abril de 2018, da Segunda Turma do Superior Tribunal de Justiça. Na ocasião, o colegiado reconheceu a responsabilidade civil do Estado, em razão de sua omissão, por não fiscalizar corretamente a construção de obras violadoras de normas ambientais. Eis a ementa:

\begin{abstract}
ADMINISTRATIVO. AGRAVO INTERNO NO RECURSO ESPECIAL. AMBIENTAL. AÇÃO CIVIL PÚBLICA. DANO AMBIENTAL E URBANÍSTICO. CONSTRUCÕES IRREGULARES. DEVER DE FISCALIZAÇÃO. OMISSÃO. RESPONSABILIDADE CIVIL DO ESTADO. CARÁTER SOLIDÁRIO, MAS DE EXECUÇÃO SUBSIDIÁRIA. PRECEDENTES.
\end{abstract}

1. A responsabilidade do Estado por dano ao meio ambiente decorrente de sua omissão no dever de fiscalização é de caráter solidário, mas de execução subsidiária, na condição de devedor-reserva. Precedentes.

2. Há responsabilidade do Estado ainda que, por meios apenas indiretos, contribua para a consolidação, agravamento ou perpetuação dos danos experimentados pela sociedade. Hipótese que não se confunde com a situação de garantidor universal.

3. No caso dos autos, ainda que o acórdão recorrido tenha entendido pela inexistência de omissão específica, os fatos narrados apontam para o nexo claro entre a conduta do Estado e o dano, constituído pela edição de normativos e alvarás autorizando as construções violadoras do meio ambiente e não implementação das medidas repressivas às obras irregulares especificadas em lei local.

Ressalte-se, os danos permanecem sendo experimentados pela comunidade há mais de duas décadas e foram declarados pelo próprio ente público como notórios.

4. O reconhecimento da responsabilização solidária de execução subsidiária enseja que o Estado somente seja acionado para cumprimento da obrigação de demolição das construções irregulares após a devida demonstração de absoluta impossibilidade ou incapacidade de cumprimento da medida pelos demais réus, diretamente causadores dos danos, e, ainda, sem prejuízo de ação regressiva contra os agentes públicos ou particulares responsáveis.

5. Agravo interno a que se nega provimento. ${ }^{8}$

Em seu voto, o relator assentou que a omissão do Distrito Federal decorreu da inércia no exercício do poder de polícia, pois

o Estado tem poder-dever de controle e fiscalização ambiental e urbanística, do qual não se desincumbe o Administrador que se limita a embargar obra erigida em área pública ou denunciá-la a outros órgãos de repressão e controle da ordem, como Ministério Público ou polícia. Essa responsabilidade dá-se por contribuir, ao se omitir, ainda que indiretamente, para o agravamento, consolidação ou perpetuação do dano.

\footnotetext{
${ }^{8}$ AgInt no REsp 1326903/DF, Rel. Ministro OG FERNANDES, SEGUNDA TURMA, julgado em 24/04/2018, DJe 30/04/2018.
} 
Em outro julgamento, reconheceu-se a responsabilidade subsidiária do Estado pela demolição de construções particulares realizadas às margens de reservatório de água, também pela omissão na fiscalização:

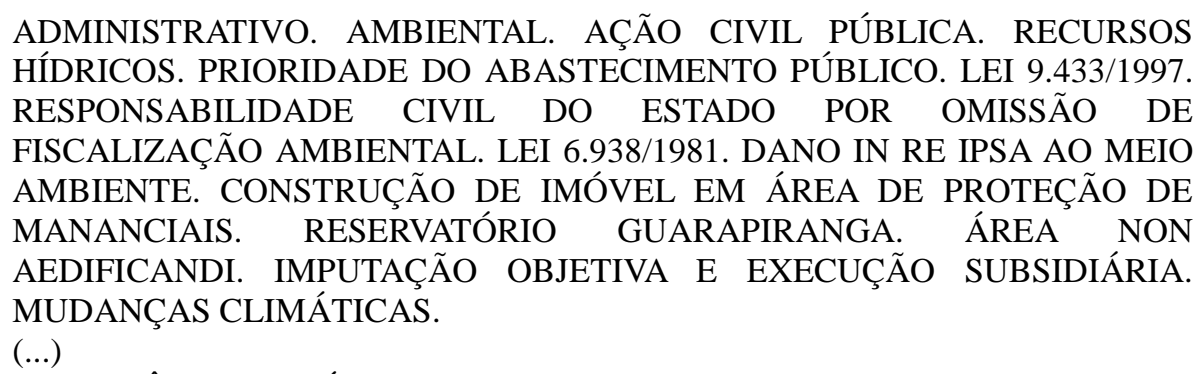
IMPORTÂNCIA DA ÁGUA 2. Indiscutível que sem água não há vida. Por força de lei, abastecimento público é uso prioritário por excelência dos recursos hídricos (art. $1^{\circ}$, III, da Lei 9.433/1997). Logo, qualquer outro emprego da água, de suas fontes e do entorno dos rios, lagos, reservatórios e fontes subterrâneas que venha a ameaçar, dificultar, encarecer ou inviabilizar o consumo humano, imediato ou futuro, deve ser combatido pelo Estado, na sua posição de guardião maior da vida das pessoas, com medidas enérgicas e eficazes de prevenção, fiscalização, repressão e recuperação.

(...) RESPONSABILIDADE CIVIL AMBIENTAL DO ESTADO POR OMISSÃO DE FISCALIZAÇÃO 9. Segundo o acórdão recorrido, deve ser excluída a responsabilização do Estado, mesmo que reconheça haver o Ministério Público notificado a Secretaria Estadual do Meio Ambiente, que não utilizou meios efetivos para sanar a violação e fazer cessar o dano.

10. Nesse ponto, o Tribunal de Justiça se distanciou da jurisprudência do STJ. Não se imputa ao Estado, nem se mostra viável fazê-lo, a posição de segurador universal da integralidade das lesões sofridas por pessoas ou bens protegidos. Tampouco parece razoável, por carecer de onipresença, exigir que a Administração fiscalize e impeça todo e qualquer ato de infração a lei. No entanto, incumbe ao Estado o dever-poder de eficazmente e de boa-fé implementar as normas em vigor, atribuição que, no âmbito do meio ambiente, ganha maior relevo diante da dominialidade pública de muitos dos elementos que o compõem e da diversidade dos instrumentos de prevenção, repressão e reparação prescritos pelo legislador.

11. Apesar de se ter por certo a inexequibilidade de vigilância ubíqua, é mister responsabilizar, em certas situações, o Estado por omissão, de forma objetiva e solidária, mas com execução subsidiária (impedimento à sua convocação per saltum), notadamente quando não exercida, a tempo, a prerrogativa de demolição administrativa ou de outros atos típicos da autoexecutoriedade ínsita ao poder de polícia.

$(\ldots)^{9}$

Esses acórdãos claramente se baseiam no princípio da proteção deficiente. O Estado é encarregado de intervir em qualquer empreendimento que ameace ou viole bens difusos, na medida em que a agressão atinge multiplicidade de pessoas, possivelmente não identificáveis. Assim, se ao Estado é proibido o excesso, por outro lado não lhe é dada a omissão na defesa de bens da coletividade, sob pena de o desenvolvimento não se ser sustentável ambiental, social e economicamente.

\footnotetext{
${ }^{9}$ REsp 1376199/SP, Rel. Ministro HERMAN BENJAMIN, SEGUNDA TURMA, julgado em 19/08/2014, DJe 07/11/2016.
} 
Sustentabilidade não é algo estranho à jurisprudência do Supremo Tribunal Federal.

A recente discussão em torno da proibição da utilização industrial do amianto é, talvez, o caso mais representativo do debate sobre sustentabilidade, avanços científicos e reflexividade política do perigo.

A Lei Federal n. ${ }^{\circ}$ 9.055/95, em seu art. $2^{\circ}$, proclamou que a "utilização condicionada do asbesto/amianto da variedade crisotila (asbesto branco), do grupo dos minerais das serpentinas, $e$ as demais fibras, naturais $e$ artificiais de qualquer origem, utilizadas para o mesmo fim, serão extraídas, industrializadas, utilizadas e comercializadas em consonância com as disposições desta Lei”. Assim, desde que cumpridas determinadas condições, era válida a utilização comercial da substância, matéria-prima comum na fabricação de telhas e caixas d'água. Tratou-se de exceção, pois os demais tipos de amianto tiveram o uso proibido em território nacional.

Alguns Estados da Federação, como São Paulo, Pernambuco e Rio Grande do Sul, porém, foram mais restritivos, vedando inclusive a utilização do amianto crisotila, causandose a impressão de que extrapolação de competência legislativa concorrente, na medida em que teriam superado as normas gerais editadas pelo ente central.

A essa conclusão chegou a Suprema Corte, em 2003, quando declarou a inconstitucionalidade de leis do Mato Grosso do Sul e de São Paulo que proibiam o amianto (ADI's 2656 e 2396).

No entanto, o avanço dos conhecimento científicos identificou que o asbesto branco (amianto crisotila) era substância cancerígena, não havendo forma para que fosse utilizado de maneira segura. Esse consenso científico ficou claro em audiências públicas promovidas pelo Supremo Tribunal Federal, na instrução da ADI 3937/SP, quando se divulgaram estudos da Organização Mundial de Saúde. As mesmas audiências públicas revelaram estudos sobre os impactos ambientais dos resíduos de amianto, não absorvíveis pelo solo, não degradáveis, cujo tratamento é caríssimo e pouco difundido.

Assim, reconheceu-se que a Lei n. $^{\circ} 9.055 / 95$ passou por processo de inconstitucionalização, decorrente da alteração do paradigma científico. Na época de sua edição, se considerava que amianto crisotila era inofensivo, mas o conhecimento humano evoluiu e atestou sua agressividade à saúde humana e ao ambiente. Portanto, o uso do amianto não ocasionava desenvolvimento sustentável ambiental, econômico ou social, pelo contrário, degradava o ambiente, os consumidores e os trabalhadores da indústria.

O ministro DIAS TOFFOLI, em seu voto, resumiu com acuidade a questão: 
Enfim, se em 1995, tolerava-se, sob certas circunstâncias e condições, a utilização da crisotila, especialmente em razão da inexistência naquele momento de substitutivos, atualmente, o consenso científico é no sentido da impossibilidade técnica do uso seguro da crisotila e da existência de substitutivo idôneo. Esse conjunto de fatores - quais sejam, (i) o consenso dos órgãos oficiais de saúde geral e de saúde do trabalhador em torno da natureza altamente cancerígena do amianto crisotila; (ii) a existência de materiais alternativos à fibra de amianto e (iii) a ausência de revisão da legislação federal, que já tem mais de 22 (vinte e dois anos) anos - revela a inconstitucionalidade superveniente (sob a óptica material) da Lei Federal n 9.055/1995, por ofensa, sobretudo, ao direito à saúde (art. $6^{\circ}$ e 196, $\mathrm{CF} / 88$ ); ao dever estatal de redução dos riscos inerentes ao trabalho por meio de normas de saúde, higiene e segurança (art. $7^{\circ}$, inciso XXII, CF/88); e à proteção do meio ambiente (art. 225, CF/88)

A Suprema Corte assumiu, assim, postura notadamente substancialista, resolvendo desacordo moral em torno de lei, que, com o avanço da tecnologia, revelou-se violadora de princípios. Cuida-se de exemplo de expansão da jurisdição constitucional, no resguardo de direitos fundamentais, a despeito de possível dificuldade contramajoritária.

Em outro julgamento (RE 627.189), o Supremo Tribunal Federal foi mais comedido, em razão da ausência do consenso científico sobre a lesividade de atividade. Cuidou-se de discussão sobre os riscos da exposição humana a linhas de transmissão de energia elétrica. $\mathrm{Na}$ ocasião, entendeu-se que o princípio da precaução não poderia restringir o exercício de atividade econômica com base em suposições. O Tribunal foi deferente aos regulamentos técnicos da OMS, não aumentando suas exigências, atento, assim, à doutrina das capacidades institucionais. Segue a ementa:

Recurso extraordinário. Repercussão geral reconhecida. Direito Constitucional e Ambiental. Acórdão do tribunal de origem que, além de impor normativa alienígena, desprezou norma técnica mundialmente aceita. Conteúdo jurídico do princípio da precaução. Ausência, por ora, de fundamentos fáticos ou jurídicos a obrigar as concessionárias de energia elétrica a reduzir o campo eletromagnético das linhas de transmissão de energia elétrica abaixo do patamar legal. Presunção de constitucionalidade não elidida. Recurso provido. Ações civis públicas julgadas improcedentes. 1. O assunto corresponde ao Tema $n^{\circ} 479$ da Gestão por Temas da Repercussão Geral do portal do STF na internet e trata, à luz dos arts. $5^{\circ}$, caput e inciso II, e 225, da Constituição Federal, da possibilidade, ou não, de se impor a concessionária de serviço público de distribuição de energia elétrica, por observância ao princípio da precaução, a obrigação de reduzir o campo eletromagnético de suas linhas de transmissão, de acordo com padrões internacionais de segurança, em face de eventuais efeitos nocivos à saúde da população. 2. O princípio da precaução é um critério de gestão de risco a ser aplicado sempre que existirem incertezas científicas sobre a possibilidade de um produto, evento ou serviço desequilibrar o meio ambiente ou atingir a saúde dos cidadãos, o que exige que o estado analise os riscos, avalie os custos das medidas de prevenção e, ao final, execute as ações necessárias, as quais serão decorrentes de decisões universais, não discriminatórias, motivadas, coerentes e proporcionais. 3. Não há vedação para o controle jurisdicional das políticas públicas sobre a aplicação do princípio da precaução, desde que a decisão judicial não se afaste da análise formal dos limites desses parâmetros e que privilegie a opção democrática das escolhas discricionárias feitas pelo legislador 
e pela Administração Pública. 4. Por ora, não existem fundamentos fáticos ou jurídicos a obrigar as concessionárias de energia elétrica a reduzir o campo eletromagnético das linhas de transmissão de energia elétrica abaixo do patamar legal fixado. 5. Por força da repercussão geral, é fixada a seguinte tese: no atual estágio do conhecimento científico, que indica ser incerta a existência de efeitos nocivos da exposição ocupacional e da população em geral a campos elétricos, magnéticos e eletromagnéticos gerados por sistemas de energia elétrica, não existem impedimentos, por ora, a que sejam adotados os parâmetros propostos pela Organização Mundial de Saúde, conforme estabelece a Lei no 11.934/2009. (...). ${ }^{10}$

\section{CONCLUSÕES}

O breve apanhado de ideias permite a formulação de algumas conclusões contemporâneas acerca da sustentabilidade e de como o Estado com ela lida.

A sustentabilidade possui vertentes ambiental, social e econômica, apresentando espectro mais amplo que o tradicional enfoque na primeira delas. Cuida-se de instituto dotado de conteúdo transnacional, pois os impactos da existência humana não respeitam fronteiras políticas ou geográficas, tampouco a noção de tempo, e a preservação do ambiente e a redução de desigualdades devem ser a tônica de ética contemporânea, informada pela solidariedade intra e intergeracional.

Assim, as novas tecnologias devem ser voltadas para a efetivação da sustentabilidade, seja ela econômica, ambiental ou social, com a ressalva de que não se podem apostar todas as fichas nos conhecimentos técnicos científicos, sendo necessário o despertar de reflexividade política dos perigos, trazendo-se o debate à arena pública/política sobre os riscos e as possíveis tragédias, e consequente mutação de paradigmas de responsabilização.

A sustentabilidade é uma busca constante do Estado, que, mesmo reduzindo seu papel como agente econômico, deve adotar modelo de governança eficiente, assegurador da boa prestação de serviços públicos (incluindo o poder de polícia), da correta regulação do mercado. A administração pública, cujo funcionamento naturalmente é agente impactador nos planos ambiental, social e econômico, vem mostrando algumas iniciativas importantes para implementar o desenvolvimento sustentável e alcançar o projeto constitucional de sustentabilidade.

Finalmente, a jurisdição constitucional, embasada em conhecimentos científicos, pode sindicar a validade de atos normativos ou administrativos que ponham em risco a

10 RE 627189, Relator(a): Min. DIAS TOFFOLI, Tribunal Pleno, julgado em 08/06/2016, ACÓRDÃO ELETRÔNICO REPERCUSSÃO GERAL - MÉRITO DJe-066 DIVULG 31-03-2017 PUBLIC 03-04-2017 sem negrito no original. 
dignidade humana, assumindo postura substancialista para a defesa da sustentabilidade ambiental, econômico e social.

\section{REFERÊNCIAS}

BARROSO, Luís Roberto. Curso de direito constitucional contemporâneo: os conceitos fundamentais e a constituição do novo modelo. 2 ed. São Paulo: Saraiva, 2010.

BARROSO FILHO, José. Desafios do desenvolvimento: a complexa integração entre o político, o social, o econômico e o jurídico - publicado na coletânea “30 anos da Constituição da República Federativa do Brasil: da teoria Constitucionalista aos Tribunais Superiores”. Coordenadores: Sidney Guerra, José Barroso Filho, Viviane Coêlho de Séllos-Knoerr. Curitiba: Instituto Memória. Centro de Estudos de Contemporaneidade, 2018.

BECK, Ulrich. A política na sociedade de risco. Tradução de Estevão Bosco. Disponível em: https://periodicos.sbu.unicamp.br/ojs/index.php/ideias/article/view/8649300/15855. Acesso em: 15 out. 2018.

BINENBOJM, Gustavo. A constitucionalização do direito administrativo no Brasil: um inventário de avanços e retrocessos. Revista Eletrônica sobre a Reforma do Estado. n. 13. março/abril/maio $2008 . \quad$ Salvador. $\quad$ disponível em http://www.direitodoestado.com.br/codrevista.asp?cod=262. Acesso em 18/10/2018.

BRASIL. Superior Tribunal de Justiça. AgInt no REsp 1326903/DF, Rel. Ministro OG FERNANDES, SEGUNDA TURMA, julgado em 24/04/2018, DJe 30/04/2018.

BRASIL. Superior Tribunal de Justiça. REsp 1376199/SP, Rel. Ministro HERMAN BENJAMIN, SEGUNDA TURMA, julgado em 19/08/2014, DJe 07/11/2016.

BRASIL. Supremo Tribunal Federal. ADI 3937/SP, Rel. Ministro MARCO AURÉLIO, Redator do acórdão Ministro DIAS TOFFOLI. Tribunal Pleno, julgado em 24/08/2017. acórdão ainda não publicado. 
BRASIL. Supremo Tribunal Federal. RE 627189, Relator Ministro DIAS TOFFOLI, Tribunal Pleno, julgado em 08/06/2016, ACÓRDÃO ELETRÔNICO REPERCUSSÃO GERAL MÉRITO DJe-066 DIVULG 31-03-2017 PUBLIC 03-04-2017.

COELHO, Inocêncio Mártires, MENDES, Gilmar Ferreira e BONET BRANCO, Paulo Gustavo. Curso de direto constitucional. 5 ed. São Paulo: Saraiva, 2010.

FARIA, José Henrique. Sustentabilidade. Anais de textos selecionados do V Seminário sobre Sustentabilidade. NEVES, Lafaiete Santos (org). Curitiba: Juruá, 2011, p. 17. - apud ANTUNES DE SOUZA, Maria Cláudia da Silva e PAVAN, Kamilla.

FREITAS, Juarez. Sustentabilidade: direito ao futuro. Belo Horizonte: Fórum, 2012.

GUARAGNI, Fábio André. A função do direito penal e os "sistemas perito". publicado na coletânea "Crimes contra a ordem econômica: temas atuais de processo e direito penal". Curitiba: Juruá, 2011.

KRELL, Andreas J. Os princípios estruturais da Constituição brasileira entre pretensão normativa e realidade social: estado democrático de direito (Estado Social - Estado Federativo - Estado Ambiental). Fórum de Direito Urbano e Ambiental - FDUA, Belo Horizonte, ano 17, n. 97, jan./fev. 2018. Disponível em: <http://www.bidforum.com.br/PDI0006.aspx?pdiCntd=250584>. Acesso em: 15 out. 2018.

ORGANIZAÇÃO DAS NAÇÕES UNIDAS. Relatório da Comissão de Meio Ambiente e Desenvolvimento da Organização das Nações Unidas, de 11 de dezembro de 1987.

ORGANIZAÇÃO DAS NAÇÕES UNIDAS. Transformando o Nosso Mundo: A Agenda 2030 para o Desenvolvimento Sustentável.

RIBEIRO NARDES, João Augusto. Constituição Federal e desenvolvimento - a importância da governança pública - publicado na coletânea "30 anos da Constituição da República Federativa do Brasil: da teoria Constitucionalista aos Tribunais Superiores." Coordenadores: Sidney Guerra, José Barroso Filho, Viviane Coêlho de Séllos-Knoerr. Curitiba: Instituto Memória. Centro de Estudos de Contemporaneidade, 2018. 
SÉLLOS-KNOERR, Viviane Coêlho e KNOERR, Fernando Gustavo. Valores constitucionais: o "dever-ser" como base de uma construção jurídica - publicado na coletânea "30 anos da Constituição da República Federativa do Brasil: da teoria Constitucionalista aos Tribunais Superiores”. Coordenadores: Sidney Guerra, José Barroso Filho, Viviane Coêlho de Séllos-Knoerr. Curitiba: Instituto Memória. Centro de Estudos de Contemporaneidade, 2018.

SILVA ANTUNES, Maria Cláudia e PAVAN, Kamilla - "NOVAS TECNOLOGIAS, SUSTENTABILIDADE E MEIO AMBIENTE SADIO E EQUILIBRADO: UM DESAFIO PARA OS DIAS ATUAIS" - disponível em http://www.indexlaw.org/index.php/conpedireview/article/view/3484 - acesso em 18/10/2018.

SHIOHARA, Mariane; SÉLLOS, Viviane. O poder público e a coletividade na promoção de políticas públicas socioambientais municipais: o projeto "seda justa" no município de nova esperança.. Revista Juridica, [S.1.], v. 1, n. 28, p. 508-524, nov. 2012. ISSN 2316-753X. Disponível em: <http://revista.unicuritiba.edu.br/index.php/RevJur/article/view/425/330>. Acesso em: 20 abr. 2020. doi:http://dx.doi.org/10.21902/revistajur.2316-753X.v1i28.425. 